\title{
Development of Phased Twin Flip-Flop Jets
}

Ganesh Raman

Sverdrup Technology, Inc.

Lewis Research Center Group

Brook Park, Ohio

and

Edward J. Rice

National Aeronautics and Space Administration

Lewis Research Center

Cleveland, Ohio

Prepared for the

ASME Winter Annual Meeting sponsored by the American Society of Mechanical Engineers

New Orleans, Louisiana, November 28-December 3, 1993 


\title{
DEVELOPMENT OF PHASED TWIN FLIP-FLOP JETS
}

\author{
Ganesh Raman ${ }^{1}$ \\ Sverdrup Technology Inc. \\ Lewis Research Center Group \\ Brookpark OH 44142 \\ Edward J. Rice ${ }^{2}$ \\ NASA Lewis Research Center \\ Cleveland $\mathrm{OH} 44135$
}

\begin{abstract}
The flip-flop nozzle is a device that can produce an oscillating jet flow without any moving parts. There is now a renewed interest in such nozzles due to their potential for use as excitation devices in practical applications. An experiment aimed at developing twin flip-flop jets that operate at prescribed frequencies and phase differences was performed. The phasing was achieved using two different nozzle interconnection schemes. In one configuration the two jets flapped inphase and in another they flapped out-of-phase with respect to each other. In either configuration the frequencies of oscillation of both jets were equal. When one of the jets was run at a constant high velocity and the velocity of the second jet was increased gradually, the higher velocity jet determined the frequency of oscillation of both jets. The two flip-flop jet configurations described in this paper could be used to excite a primary jet flow in either an anti-symmetric (sinuous) or a symmetric (varicose) mode.
\end{abstract}

\section{NOMENCLATURE}

B larger dimension of flip-flop attachment

b larger dimension of rectangular slot nozzle

d diameter of feedback tube

$d_{c}$ diameter of interconnection tube

\footnotetext{
${ }^{1}$ Research Engineer

${ }^{2}$ Lewis Distinguished Research Associate, Retired
}

f frequency of oscillation

$\mathrm{H}$ smaller dimension of flip-flop attachment

h smaller dimension of rectangular slot nozzle

$\mathrm{L} \quad$ length of feedback tube

$\mathrm{L}_{\mathrm{c}} \quad$ length of interconnection tube

$L_{\text {if }} \quad$ axial dimension of flip-flop nozzle attachment

$\mathrm{P}_{\mathrm{a}} \quad$ ambient pressure

$\mathrm{P}_{\mathrm{o}} / \mathrm{P}_{\mathrm{a}} \quad$ nozzle pressure ratio (NPR)

$\mathrm{S}, \mathrm{S}$ aspect ratio, $\mathrm{B} / \mathrm{H}, \mathrm{b} / \mathrm{h}$

w width of feedback slot

\section{INTRODUCTION}

In the 1970's pioneering work on the flip-flop nozzle was done by Viets and his associates (Viets (1975), Viets et al (1975a)). They showed that it is possible to produce and sustain an oscillation of a subsonic jet flow without any moving parts. Such oscillatory jets have applications in fuel injectors (Viets et al (1975a)), foam spreading (Viets et al (1975b)), unsteady ejectors (Viets (1981)), and in two-phase flows (Morris et al (1992)). In our previous work (Raman et al (1993)) the operation of the flip-flop jet nozzle was extended to supersonic flows. The potential for using such a device for the control of practical shear flows is the motivation for the present effort. Excitation from acoustic drivers 
used for controlling shear flows in fundamental research experiments (Crow and Champagne (1971), Ahuja et al (1982), Raman and Rice (1991)) are not likely to be effective under practical conditions. In recent years a variety of shear flow control devices have been developed. Examples of novel excitation devices include the "Whistler nozzle" (Hill and Greene (1977)), the use of piezoelectric actuators (Wilste and Glezer (1993)), jets excited by natural and "induced" screech (Rice and Raman (1993)), and dual-mode acoustic excitation that results in "bifurcated" jets (Parekh et al (1987)). Other techniques for flow manipulation and mixing enhancement include the use of tabs (Ahuja and Brown (1989), Zaman et al (1993)), counterflow (Strykowski et al (1992)), hydrodynamic excitation (Brown and Ahuja (1990)) and auxiliary jet impingement (Davis (1982)). The flip-flop jet provides yet another possibility for the control of practical shear flows.

There has been a recent renewal of interest in flip-flop jets and similar devices. This is due to the need for a practical excitation device for the control of mixing and noise of supersonic jets. Schreck (1992a) reported work on an oscillating jet produced by the alternate pumping of air from both sides of the jet. In a subsequent study Schreck (1992b) eliminated the pumping and used screech amplified by a resonant cavity to excite the jet. However, it appears that such nozzles are unsuitable for use as primary nozzles due to large losses in thrust. The thrust loss in a flip-flop nozzle was measured by Viets (1975) to be between 10 and 40 percent. This thrust loss may be lower in the nozzle of Schreck (1992b) because the flow does not actually attach to both walls. However, estimates of the thrust loss for this nozzle are currently unavailable.

There have been previous attempts (Viets (1975)) to interconnect the various elements of flip-flop nozzles in order to achieve some desired phase relationships between neighboring nozzles. However, in spite of the various configurations attempted, oscillation of the flow was not achieved. Viets (1975) tested a nine element nozzle for use as the primary nozzle in a low area ratio ejector test, but each nozzle element oscillated independently with no specific phase relationship to the other nozzles. It should be noted that in subsequent work, Viets et al (1981) did operate a series of mechanically controlled multiple fluidic jets at controllable phases. However, the oscillating pressure difference was created by rotating valves on either side of the jet. The valves were rotated out of phase with each other, so that one was open when the other was closed. The resulting flow always attached to the closed side and thus provided a jet that oscillated from side to side. Their (Viets et al (1981)) motivation was not the development of practical excitation devices but the design and development of a pilot gust tunnel using a linear array of such nozzles.

\section{SCOPE}

The objective of this work is to develop twin flip-flop jets that can operate at a controllable frequency and phase difference. Schemes to interconnect a pair of flipflop jet nozzles and operate them either in-phase (0 degrees phase difference) or out-of-phase (180 degrees phase difference) with respect to each other are described here. In contrast to the Viets (1981) work using rotating valves that was described earlier, the present work attempts to interconnect two flip-flop nozzles without moving parts, using only feedback tube interconnections. To our knowledge, work on such twin flip-flop jets operating at a desired phase relationship and controllable frequency of oscillation has not been reported before. The twin jets can provide either symmetric or anti-symmetric fluid dynamic perturbations that could be used to excite a larger scale primary flow.

The work described in this paper should be viewed as a unique "proof of concept" type of experiment. However, the optimization of nozzle parameters and interconnection tubes was not attempted here. For such an excitation technique to be viable for use in practical applications, flip-flop exciters must be designed for optimal performance.

\section{EXPERIMENTAL DETAILS}

A schematic of the flip-flop jet nozzle reproduced from Raman et al (1993) is shown in Figure 1. The nozzle has three parts: the convergent rectangular slot nozzle, a nozzle attachment with control ports, and a feedback tube that connects the control ports. When the jet from the rectangular slot nozzle (see Figure 1) exhausts into the region between the two plates of the nozzle attachment, the jet could attach to either wall (Coanda effect). A small pressure gradient could cause the jet to detach from one wall and attach to the other. With the help of a feedback tube this process can be repeated. Details of the operation of such nozzles are available in 

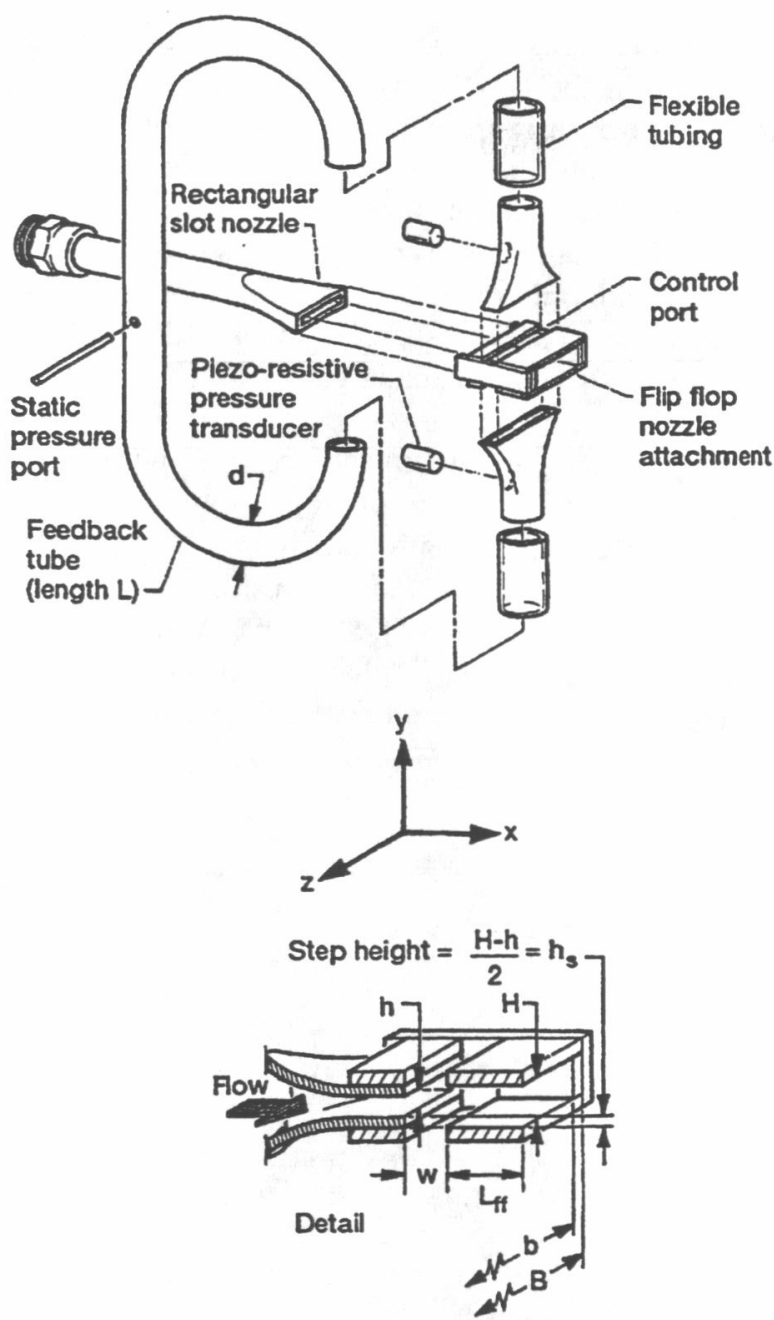

Figure 1. - Schematic of flip-flop jet nozzle (reproduced from Raman et al (1993)).

the paper by Viets (1975). The facility and nozzle used for the present study were previously described in detail by Raman et al (1993). Therefore, only a brief description is given here.

In our previous work (Raman et al (1993)) it was shown that the flapping frequency of the jet and the pressure oscillation frequency in the feedback tube were the same. This was confirmed by making simultaneous measurements of the velocity fluctuations in the shear layer and pressure fluctuations in the feedback tube using hot-wires and piezoresistive transducers. Furthermore, hot-wires placed on either side of the jet exit indicated that the velocity fluctuations at those two locations were out-of-phase. This was also true of the pressure fluctuations measured at either end of the feedback tube. For this reason, the signal from the piezoresistive pressure transducers in the feedback tube
Table I NOZZLE DIMENSIONS

\begin{tabular}{|c|c|}
\hline $\begin{array}{c}\text { NOZZLE } \\
\text { PARAMETER }\end{array}$ & $\begin{array}{l}\text { DIMENSION } \\
(\mathrm{mm})\end{array}$ \\
\hline h & 2.34 \\
\hline b & 19.05 \\
\hline $\mathrm{s}$ & 8.15 \\
\hline $\mathrm{H}$ & 7.0 \\
\hline B & 19.05 \\
\hline$S$ & 2.72 \\
\hline w & 3.17 \\
\hline $\mathrm{d}, \mathrm{d}_{\mathrm{c}}$ & 10.7 \\
\hline $\mathrm{L}_{\mathrm{ff}}$ & 15.87 \\
\hline L & 711 \\
\hline $\begin{array}{c}\mathrm{L}_{\mathrm{c}} \\
\text { (in-phase) }\end{array}$ & 235 \\
\hline $\begin{array}{c}\mathrm{L}_{\mathrm{c}} \\
\text { (out-of-phase) }\end{array}$ & 381 \\
\hline
\end{tabular}

(see Fig. 1) was sufficient to determine the flapping frequency and relative phase of the flip-flop jet. The unsteady pressure signals were analyzed using a 2 channel spectrum analyzer. The frequency was determined from the power spectrum. In addition, the cross-spectral phase provided the average phase difference between the two ends of the feedback tube, or between two symmetric locations in the feedback tubes of two different nozzles (for the twin jet configurations). 


\section{TWIN JET CONFIGURATIONS}

Figure 2 shows the two interconnection configurations for the jets in-phase and out-of-phase. The nozzle and interconnection tube dimensions used for the twin flipflop jet study are given in Table I for one of the nozzles. The other nozzle had the same dimensions with the exception of $\mathrm{H}(6.5 \mathrm{~mm})$ and $\mathrm{S}(2.93)$. Figure 2(a) represents the jets in-phase configuration, in which the top control ports of both jets ( 1 and 2) were connected to each other and the bottom control ports of the two jets ( 1 and 2$)$ were connected to each other. The top and bottom interconnection tubes were of equal length ( $\mathrm{L}_{\mathrm{c}}$ (in-phase $)=235 \mathrm{~mm}$ ). Figure 2 (b) represents the jets out-of-phase configuration. Here the top control port of jet 1 was connected to the bottom control port of jet 2 , and the bottom control port of jet 1 was connected to the top port of jet 2. Again, both the interconnection tubes were of the same length $\left(\mathrm{L}_{\mathrm{c}}\right.$ (out-of-phase) $=381$ $\mathrm{mm}$ ), although, they were longer than those used for the in-phase configuration.

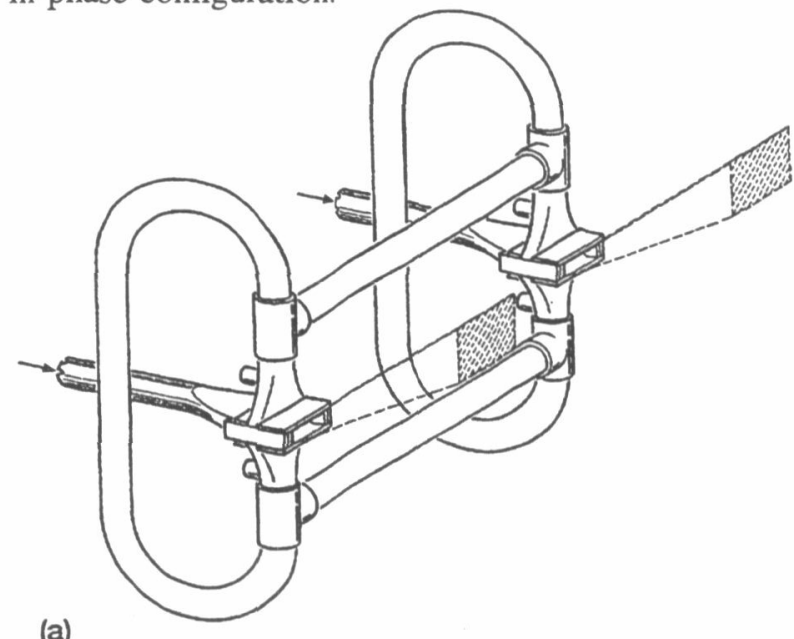

(a)

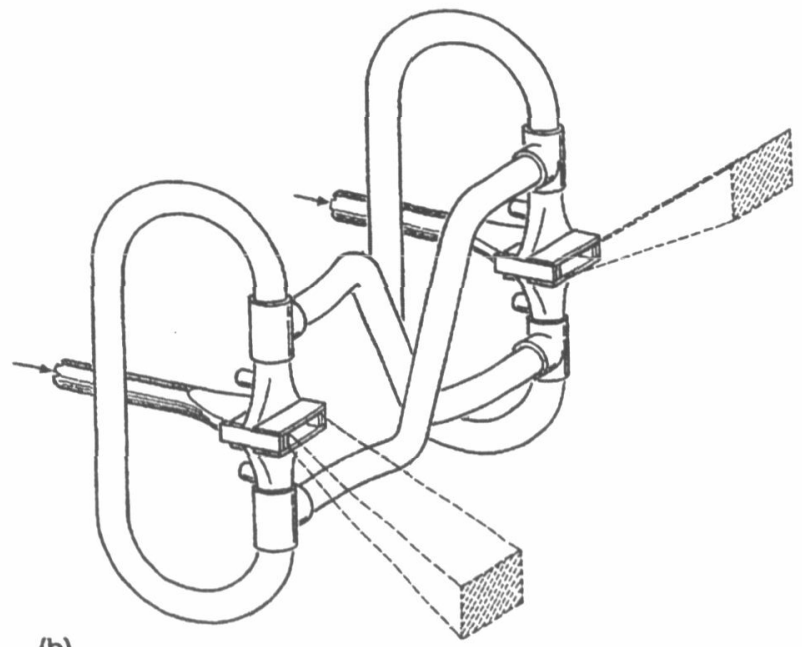

(b)

Figure 2. - Schematic of the twin jet nozzle interconnection schemes. (a) Jets in-phase configuration. (b) Jets out-of-phase configuration.
Although the present work discusses the results of jets operating in the two configurations, no attempt was made to optimize the length or volume of the interconnection tubes. Several other interconnection schemes were tried but these attempts met with little success. For example, the configurations in Figures 2(a) and 2(b) with only the interconnection tubes (with the feedback tubes sealed off) did not work. Figure 3(a,b) shows flow visualization photographs of the jets out-ofphase. The visualization was carried out at very low speeds $(<10 \mathrm{~m} / \mathrm{s})$ and was made possible by filling the plenum chamber with smoke and illuminating the flowfield with bright continuous light $(750 \mathrm{~W})$. The jets are seen to flap towards each other in 3(a) and away from each other in 3(b). Similar flow visualization records exist for the jets-in-phase configuration but are not reproduced here in the interest of conciseness.
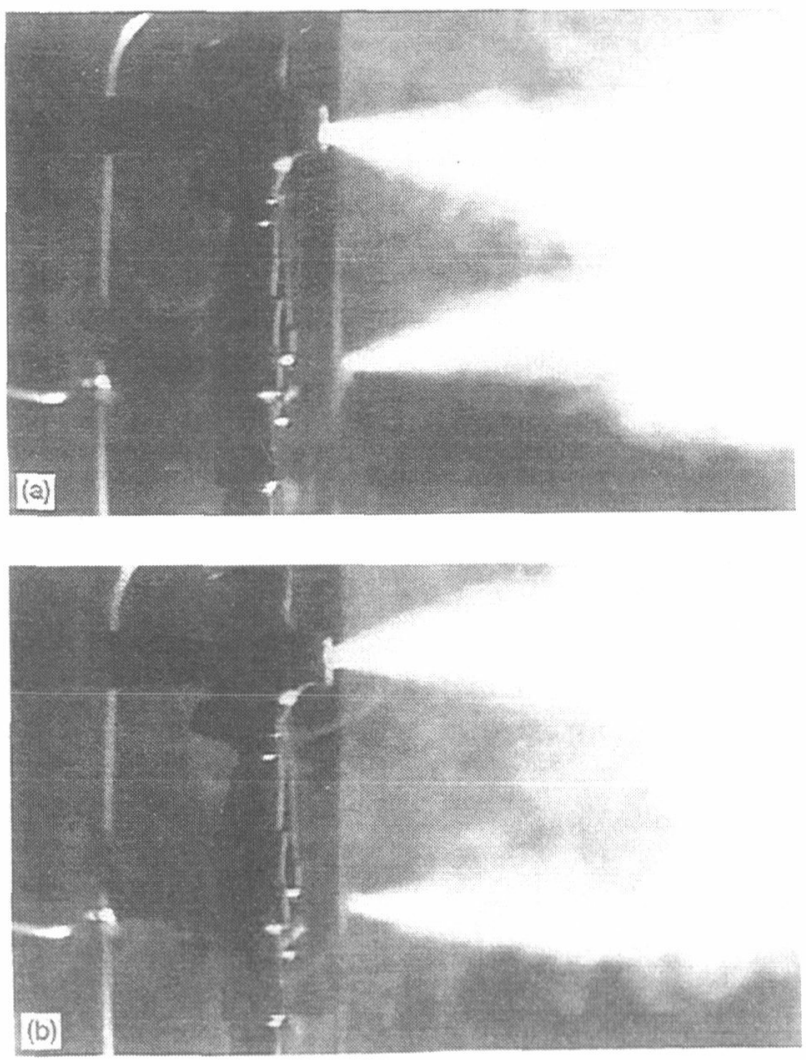

Figure 3. - Flow visualization of twin flip-flop jets (For the configuration shown in figure 2(b)). (a) Jets out-of-phase, with both jets flapping towards each other. (b) Jets out-of-phase, with both jets flapping away from each other. 


\section{RESULTS AND DISCUSSION}

\section{TWIN JETS RUN INDEPENDENTLY}

Figure 4 shows the frequency of oscillation versus nozzle pressure ratio (NPR) for the twin flip-flop jets, both of which were run independently without any interconnection of the two nozzles. In the absence of the interconnection tubes each nozzle operated independently with no specific phase relationship to the other nozzle. Since the nozzles were not identical (due to manufacturing imperfections), they operated at slightly different frequencies. For a fixed feedback tube length and diameter the frequency of oscillation of both flip-flop jets was seen to increase with an increase in the nozzle pressure ratio.

Simultaneous measurements of the unsteady pressures from both the pressure transducers mounted on either end of the feedback tube of one of the nozzles showed the signals to be 180 degrees out of phase. For either nozzle the oscillating pressure difference between the two ends of the feedback tube was measured to be about $14.2 \mathrm{KPa}$ (peak-to-peak) at a nozzle pressure ratio of 1.8. It is this oscillating pressure difference and the alternate pressure equalization through the feedback tube that causes the flapping of the jet. This pressure equalization process, which was briefly discussed by Viets (1975), is the subject of an ongoing investigation and will not be discussed any further here.

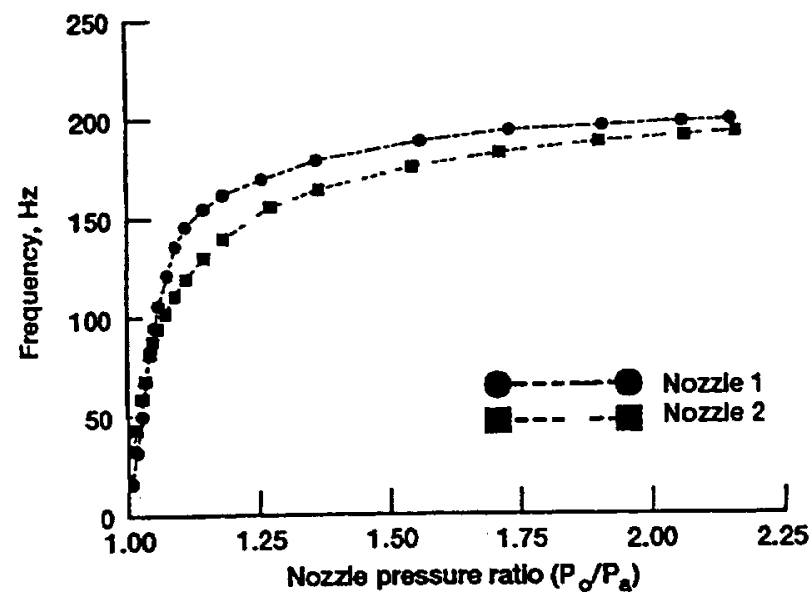

Figure 4. - Frequency versus nozzle pressure ratio for the twin jets operating independently.

\section{TWIN JETS IN-PHASE}

Figure 5(a) shows the frequency versus nozzle pressure ratio for the twin jets interconnected in the in-phase configuration. As stated before, the oscillation frequency was obtained from the spectrum of the signal from the unsteady piezoresistive pressure transducers in the feedback tubes of both jets. The frequency of oscillation of both jets were equal despite the fact that the nozzles showed different frequency characteristics when operated independently. The frequency of oscillation varied from about 10 to $170 \mathrm{~Hz}$.

The cross-spectrum phase of signals from two symmetrically located pressure transducers in the feedback tubes of the two nozzles provided the phase difference ( 0 degrees) between the two jets, which indicated that they were oscillating in-phase over the entire nozzle pressure ratio range (Figure 5(b)). Twin flip-flop jets in this configuration used on either side of a larger scale primary flow can be used to excite the anti-symmetric (sinuous) mode.
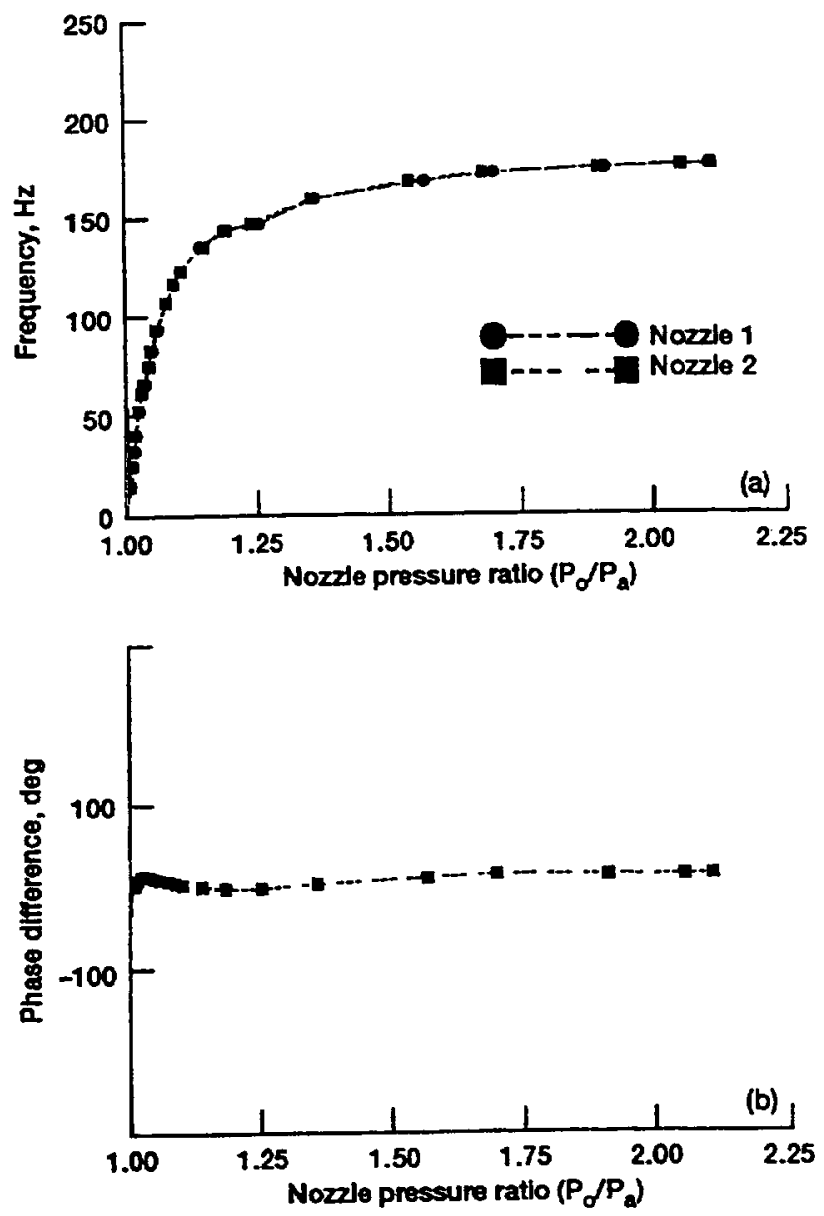

Figure 5. - Twin jets in-phase, with both jets operated at the same velocities. (a) Frequency of oscillation versus nozzle pressure ratio. (b) Phase difference between the two jets versus nozzle pressure ratio. 


\section{TWIN JETS OUT-OF-PHASE}

Figures 6(a) shows the frequency of oscillation versus nozzle pressure ratio for the twin jets interconnected in the out-of-phase configuration. The frequencies of the oscillations of both jets were again equal. The frequency of oscillation here varied from 10 to $155 \mathrm{~Hz}$. The difference in the frequency of oscillation between the two configurations was due to the different lengths and volumes of interconnection tubes which resulted in a different equivalent feedback tube length for the two configurations (see Table I). The interconnection tubes for the out-of-phase configuration were longer, resulting in lower frequencies of oscillation.

The pressure signals from two symmetrically located sensors in the feedback tubes of the two nozzles were about 180 degrees out-of-phase, which indicated that the jets were oscillating out-of-phase over the entire nozzle pressure ratio range(Figure 6(b)). Flip-flop jets in the out-of phase configuration used on either side of a larger scale primary flow can be used to excite the symmetric (varicose) mode.
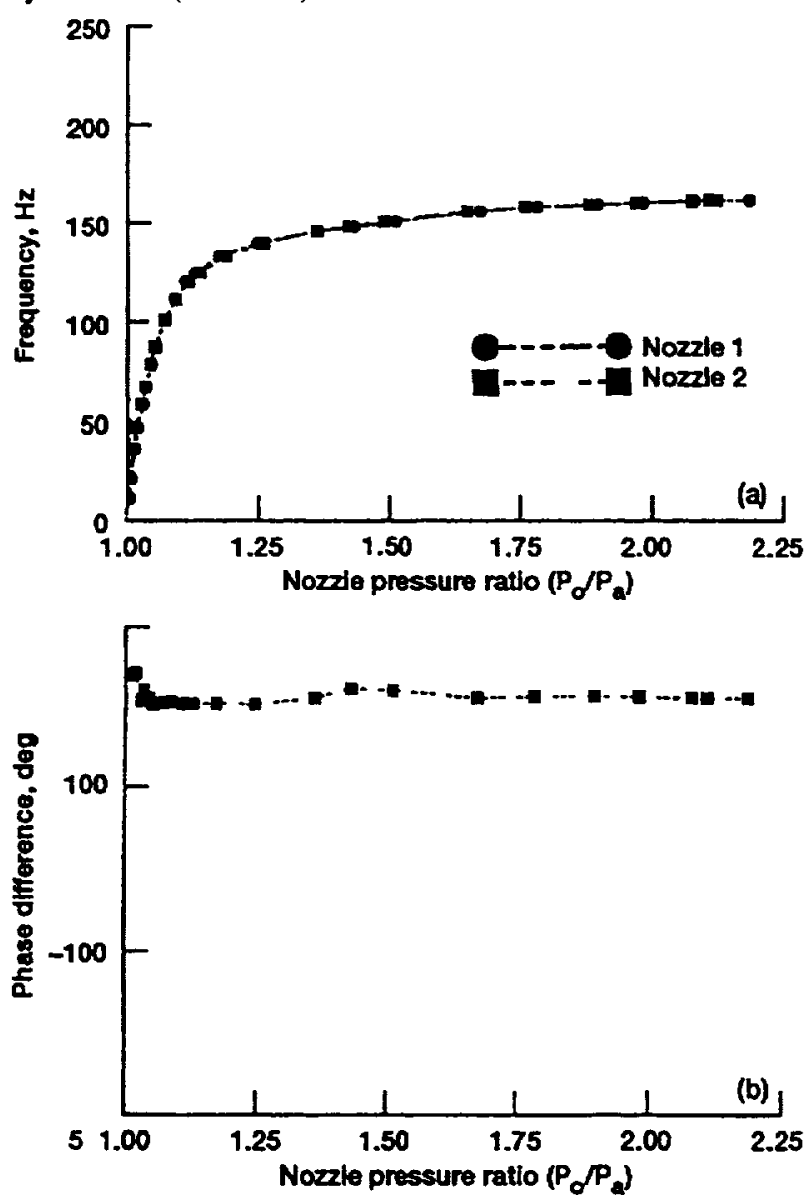

Figure 6. - Twin jets out-of-phase, with both jets operated at the same velocities. (a) Frequency of oscillation versus nozzle pressure ratio. (b) Phase difference between the two jets versus nozzle pressure ratio.

\section{PHASED TWIN JETS AT DIFFERENT VELOCITIES}

Figure $7(a, b)$ shows the frequency of oscillation and phase difference between the two jets versus nozzle pressure ratio for twin jets operating at different velocities. For these tests nozzle 2 was run at a constant (approximately) nozzle pressure ratio of 2.1 , while that of nozzle 1 was varied gradually from 1.1 to 1.8. The frequency of oscillation, however, remained constant (for both jets) at around $170 \mathrm{~Hz}$ for the inphase configuration (Figure 7 (a)) and around $155 \mathrm{~Hz}$ for the out-of-phase configuration (Figure 8(a)). As mentioned earlier, this difference in the frequency of oscillation between the two configurations was due to the different lengths and volumes of interconnection tubes for the two configurations.
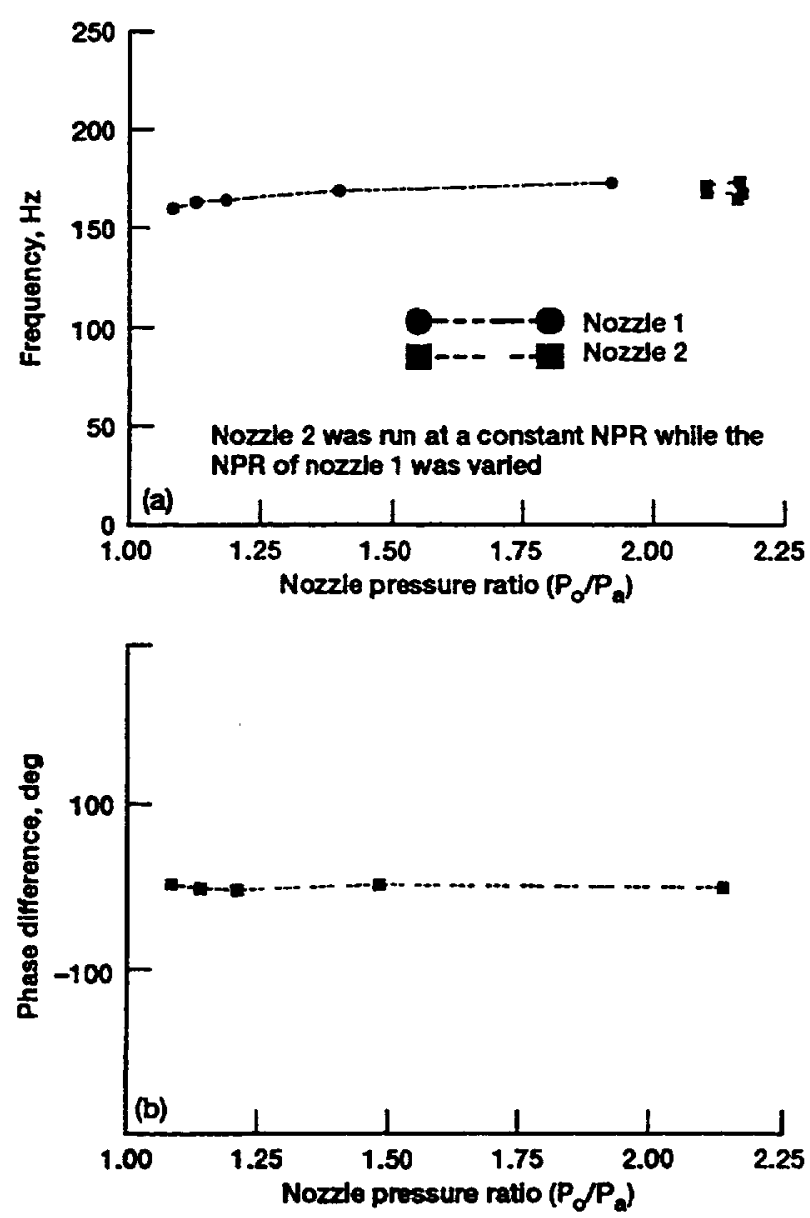

Figure 7. - Twin jets in-phase, with both jets operated at different velocities. (a) Frequency of oscillation versus nozzle pressure ratio. (b) Phase difference between the two jets versus nozle pressure ratio. 
The nozzle that was operating at a constant (high) nozzle pressure ratio in Figures 7 (a) and $8(a)$ was controlling the frequency of oscillation of both jets, while the nozzle that was operating at lower nozzle pressure ratios was behaving as a "slave" jet. This is an important finding in itself because the twin flip-flop configuration now provides the means to control the frequency of oscillation of one of the jets that is independent of the nozzle pressure ratio of that jet. With the twin jet configuration, the control jet could be used to keep the frequency of a "slave" jet constant over the range of nozzle pressure ratios of the "slave" jet. From Figures 7(b) and 8(b) it can be seen that even when the jets were operated at different speeds it was possible to maintain either the in-phase (Figure 7(b)) or the out-of-phase (Figure 8(b)) relationship between the two jets.
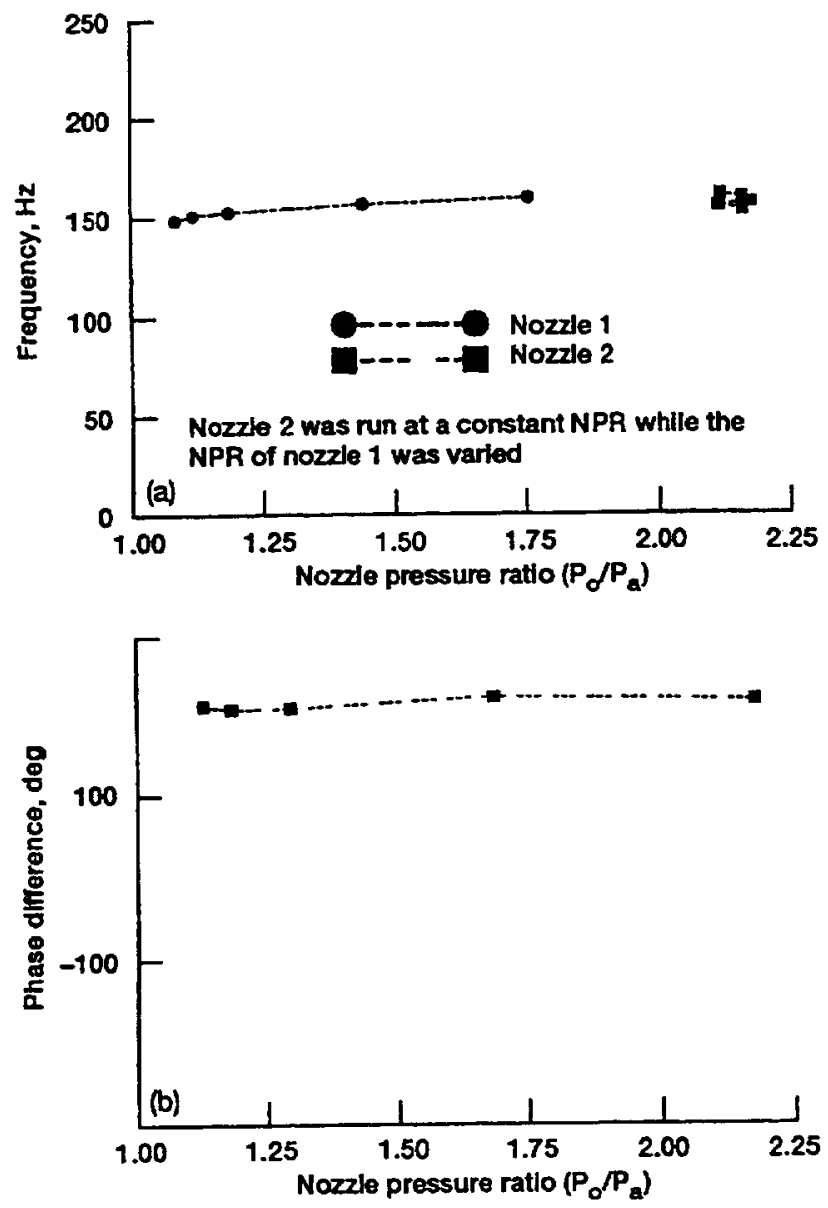

Figure 8. - Twin jets out-of-phase, with both jets operated at different velocities. (a) Frequency of oscillation versus nozle pressure ratio. (b) Phase difference between two jets versus nozzle pressure ratio.

\section{COMMENTS ON APPLICABILITY}

For the flip-flop exciter system to be attractive for use in practical applications, exciter nozzles must be designed for optimal performance. For the efficient operation of such a system with minimum thrust loss, the mass flux through the exciter jets should be negligible compared to that through the primary jet. Consequently, the dimensions of the exciter jets need to be relatively small, yet the unsteady excitation levels in the shear layer of the primary jet need to be large.

The important parameters to be considered for the efficient operation of a primary jet with a flip-flop exciter system are: frequency matching (between exciter and primary flow instability), nozzle sizing, velocity perturbation level produced, and selection of the appropriate mode of excitation (anti-symmetric or symmetric, depending on the primary flow instability). Future work should focus on achieving the goals mentioned above.

\section{NOTE ON MEASUREMENT UNCERTAINTY}

Estimates for the uncertainty in the measurements presented in this work were obtained using the methods described by Moffat (1985). The calibration uncertainty, which takes into account the uncertainties associated with the supply pressure, static pressure probe, and the pressure transducers was estimated to be about $1.5 \%$. In addition, the first order uncertainty was estimated to be about $0.3 \%$. The resultant total uncertainty was $1.529 \%$.

\section{CONCLUDING REMARKS}

(1) It was found that it is possible to interconnect two flip-flop nozzles to operate in-phase or out-of-phase. Despite the fact that the nozzles were not identical (due to manufacturing imperfections), the jets operated at the same frequency when the feedback loops were interconnected. This frequency "locking" was observed in both configurations (in-phase and out-of-phase). With such multiple, small scale, interconnected devices it would be possible to excite a larger scale primary flow in either an anti-symmetric (flapping) or a symmetric (plane wave) mode.

(2) When one of the jets was run at a constant high velocity and the velocity of the other jet was increased gradually, the higher constant velocity jet determined 
the frequency of oscillation of both jets. Despite the unequal velocities the jets were capable of operating in either the in-phase or the out-of-phase configuration.

(3) In this paper a unique "proof of concept" type of experiment was described. However the optimization of nozzle parameters and interconnection tubes was not attempted here. For this technique to be viable in practical applications, flip-flop exciters must be designed for optimal performance.

\section{ACKNOWLEDGEMENTS}

The authors would like to thank the following individuals for contributing to this work: Dr. B. Reichert, Dr. J. Wilson, Dr. K. Dugas, Mr. M. Hailye, Mr. D. Cornelius and Mr. R. Fallert. This work would not have been possible if not for the extensive ground work done by Dr. H. Viets and his associates.

\section{REFERENCES}

Ahuja, K.K., Lepicovsky, J., Tam, C.K.W., Morris, P.J., and Burrin, R.H., 1982, "Tone-excited Jets, Theory and Experiments", NASA CR-3538.

Ahuja, K.K., and Brown, W.H., 1989, "Shear Flow Control by Mechanical Tabs", AIAA Paper 89-0994.

Brown, W.H., and Ahuja, K.K., 1990, "Jet Mixing Enhancement by Hydrodynamic Excitation", AIAA Paper 90-4005.

Crow, S.C., and Champagne, F.H., 1971, "Orderly Structure in Jet Turbulence", J. Fluid Mech., Vol. 48, pp. 547-591.

Davis, M.R., 1982, "Variable Control of Jet Decay", AIAA J., Vol. 20, pp. 606-609.

Hill, W.G., and Greene, P.R., 1977, "Increased Turbulent Jet Mixing Rates Obtained by Self-Excited Acoustic Oscillations," Journal of Fluids Engineering, Transactions of the ASME, pp 520-525.

Moffat, R.J., 1985, "Using Uncertainty Analysis in the Planning of an Experiment," Journal of Fluids Engineering, Trans. ASME, Vol. 107, pp 173-178.

Morris, G.J., Jurewicz, J.T., and Palmer, G.M., 1992, "Gas-Solid Flow in a Fluidically Oscillating Jet", Joumal of Fluids Engineering, Trans ASME, Vol. 114, pp. 362-366.

Parekh, D.E., Reynolds, W.C., and Mungal, M.G., 1987, "Bifurcation of Round Air Jets by Dual-Mode Acoustic Excitation", AIAA Paper 87-0164.

Raman, G., and Rice, E.J., 1991, "Axisymmetric Jet Forced by Fundamental and Subharmonic Tones," AIAA J., Vol. 29, pp. 1114-1122.
Raman, G., Hailye, M., and Rice, E.J., 1993, "FlipFlop Jet Nozzle Extended to Supersonic Flows", AIAA J., Vol. 31, No. 6, pp. 1028-1035.

Rice, E.J., and Raman, G., 1993, "Enhanced Mixing of a Rectangular Supersonic Jet by Natural and Induced Screech", AIAA Paper 93-3263.

Schreck, S., Ho, C.M., and Sarmiento, 1992a "Noise Radiated from Axisymmetric and Asymmetric Jets," AIAA Paper 92-02044.

Schreck, S., 1992b "Application of a Flip-Flop Nozzle on Plume Mixing Enhancement", Presented at the First NASA/Industry High Speed Research, Nozzle Symposium, NASA LeRC, Cleveland OH, Nov. 17-19, 1992 ( to be published as a NASA CP).

Strykowski, P.J., Krothapalli, A., and Wishart, D., 1992, "The Enhancement of Mixing in High Speed Heated Jets Using a Counterflowing Nozzle", AIAA Paper 92-3262.

Wiltse, J.M., and Glezer, A., 1993, "Manipulation of Free Shear Flows using Piezoelectric Actuators", Submitted to J. Fluid Mech.

Viets, H., 1975, "Flip-Flop Jet Nozzle", AIAA J., Vol. 13, pp 1375-1379.

Viets, H., Blaster, D., Toms, H.L. Jr., 1975a, "Time Dependent Fuel Injectors," AIAA Paper 75-1305.

Viets, H., Balster, D., and Toms, H.L. Jr., 1975b, "Feasibility study of Unsteady Foam Generators", DOD-AGFSRS-75-6, Wright-Patterson Air Force Base. Viets, H., 1981, "Unsteady Ejectors," Proceedings of the NATO/AGARD Meeting on Fluid Dynamics of Jet Flows with Applications to V/STOL, NATO/AGARD CP-308, pp. 21.1-21.12.

Viets, H., Ball, M., and Piatt, M., 1981, "Experiments in a Subscale Pilot Gust Tunnel," AIAA J., Vol. 19, pp. 820-822.

Zaman, K.B.M.Q., Reeder, M.F., and Samimy, M., 1993, " Control of an Axisymmetric Jet Using Vortex Generators", Submitted to Phys. Fluids A. 

Public reporting burden for this collection of information is estimated to average 1 hour per response, including the time for reviewing instructions, searching existing data sources, gathering and maintaining the data needed, and completing and reviewing the collection of information. Send comments regarding this burden estimate or any other aspect of this collection of information, including suggestions for reducing this burden, to Washington Headquarters Services, Directorate for information Operations and Reports. 1215 Jefferson Davis Higtway, Sutte 1204, Arlington, VA 22202-4302, and to the Office of Management and Budget, Paperwork Reduction Project (0704-0188), Washington. DC 20503.

\begin{tabular}{|l|l|l}
\hline 1. AGEMCY USE ONLY (Leave blank) & $\begin{array}{c}\text { 2. AEPOAT DATE } \\
\text { November } 1993\end{array}$ & $\begin{array}{r}\text { 3. REPORT TYPE AND DATES COVERED } \\
\text { Technical Memorandum }\end{array}$ \\
\hline
\end{tabular}

4. TILE AND SUBTITLE

Development of Phased Twin Flip-Flop Jets

6. AUTHOR(S)

Ganesh Raman and Edward J. Rice

\section{FUNDING NUMBERS}

7. PERforiming ORGANZATHON MAME(S) AMD ADDRESS(ES)

National Aeronautics and Space Administration

Lewis Research Center

Cleveland, Ohio 44135-3191

9. SPONSORINGMONITORING AGENCY NAME(S) AND ADDRESS(ES)

National Aeronautics and Space Administration

Washington, D.C. 20546-0001
WU-505-62-52

8. PERforming organization

REPORT NUUBER

E-7609
10. SPONSORINGMIONTTORING AGENCY REPORT NUMBER

NASA TM-106404

\section{SUPPLEMENTARY NOTES}

Prepared for the ASME Winter Annual Meeting, sponsored by the American Society of Mechanical Engineers, New Orleans, Louisiana, November 28-December 3, 1993. Ganesh Raman, Sverdrup Technology, Inc. Lewis Research Center Group, 2001 Aerospace Parkway, Brook Park, Ohio 44142 (work funded by NASA Contract NAS3-25266). Responsible person, Edward J. Rice, (216) $433-3607$.

12. DISTREBUTION/AVALLABILTY STATEMENT 12b. DISTRIBUtion CODE

Unclassified - Unlimited

Subject Category 02

\section{ABSTRACT (Moximum 200 worde)}

The flip-flop nozzle is a device that can produce an oscillating jet flow without any moving parts. There is now a renewed interest in such nozzles due to their potential for use as excitation devices in practical applications. An experiment aimed at developing twin flip-flop jets that operate at prescribed frequencies and phase differences was performed. The phasing was achieved using two different nozzle interconnection schemes. In one configuration the two jets flapped in-phase and in another they flapped out-of-phase with respect to each other. In either configuration the frequencies of oscillation of both jets were equal. When one of the jets was run at a constant high velocity and the velocity of the second jet was increased gradually, the higher velocity jet determined the frequency of oscillation of both jets. The two flip-flop jet configurations described in this paper could be used to excite a primary jet flow in either an anti-symmetric (sinuous) or a symmetric (varicose) mode.

\section{SUBJECT TERMS}

Flip-Flop jets; Twin jets; Acoustic excitation; Unsteady jets; Oscillatory jets; Excitation devices; Shear flow control; Unsteady ejectors

15. NUWBER OF PAGES 10

16. PRICE CODE $\mathrm{A} 02$

\begin{tabular}{l|c|}
\hline $\begin{array}{l}\text { 17. SECURTY CLASSIFICATION } \\
\text { OF REPORT } \\
\text { Unclassified }\end{array}$ & $\begin{array}{c}\text { 18. SECURITY CLASSIFICATION } \\
\text { OF THIS PAGE } \\
\text { Unclassified }\end{array}$ \\
\hline
\end{tabular}

19. SECURITY CLASSIFICATION OF ABSTRACT Unclassified
20. LIMITATION OF ABSTRACT 


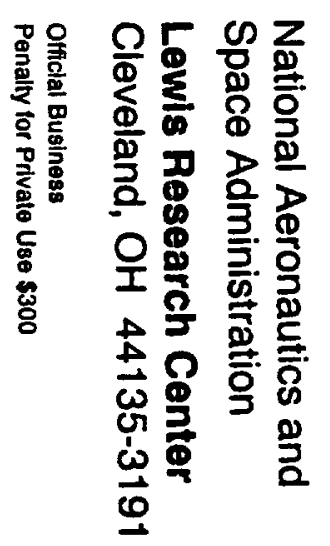




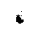

